\title{
Clinical Medical Students' Preferred Teaching Methods: A Study at the National Defense University of Malaysia
}

\author{
Sheikh Salahuddin Ahmed and Sagili Chandrasekhara Reddy
}

\section{ABSTRACT}

Background: Providing appropriate teachings in the curriculum have a great impact on learning by the students.

Objectives: The aim of this study was to determine the clinical undergraduate medical students' preferred teaching methods provided by the medical educators.

Material and Methods: This study was conducted on 89 medical students in the 4th and 5th year of the Faculty of Medicine and Defense Health, National Defense University of Malaysia, from 1st November 2019 to 31st July 2020. Each of the students was approached with a structured questionnaire for their responses to determine their preferred teaching methods.

Results: Out of 89 students, 46 were male $(51.7 \%)$; the mean age of the study students was 23.5 years. Among the various teaching methods, bedside teaching was the most preferred $(\mathbf{7 6 . 4 \%})$ one followed by lectures $(14.6 \%)$, tutorials $(\mathbf{7 . 9 \%})$ and seminars $(1.1 \%) .66 .3 \%$ of students would use elearnings' uploaded teaching materials, whereas the remainder would not. Bedside demonstrations of clinical skills by the tutors were preferred by $\mathbf{7 7 . 5 \%}$ of students. Practicing clinical skills by the students on a real patient rather than on a mannequin or a simulated patient was preferred by $94.4 \%$ of students. Regarding case discussions, problem-based learnings (PBL) were preferred by $80 \%$ of students.

Conclusions: Bedside teachings, demonstrations of clinical skill by a teacher, practicing skills by the students on a real patient rather than on a simulated patient or a mannequin, and PBLs are highly preferred by the students. Adequate teaching materials uploaded in the e-learning management system provide a good source for the teachings and learnings.

Keywords: Teaching methods, medical educators, teaching preference; clinical medical students; medical education.

\section{INTRODUCTION}

Learning by medical students is influenced by several factors that include teachings, the quality of the curriculum, learning environment and support materials provided by a medical institution as well as by the characteristics of the students. Learning is an active process in which the student and teacher have to work mutually to make the knowledgesharing process enjoyable and easier for comprehension [1]. The purpose of teaching is to facilitate learning and encourage the students to learn more effectively.

In medical education, particularly in clinical placement, there are various tools of teaching like lectures, tutorials, seminars, bedside teaching, clinical skill labs (CSL), selfdirected learning (SDL), attending clinics, ward rounds and conferences, computer-based learning, and classes with interdisciplinary interaction. Bedside teaching is defined as
Submitted : March 09, 2021

Published : March 30, 2021

ISSN: 2593-8339

DOI: $10.24018 /$ ejmed.2021.3.2.762

Sheikh Salahuddin Ahmed

Department of Internal Medicine, Faculty of Medicine and Defense Health, National Defense University of Malaysia, Kuala Lumpur, Malaysia. Department of Medicine, Royal College of Surgeons in Ireland and University College, Dublin, Malaysia Campus, Penang, Malaysia.

\section{Sagili Chandrasekhara Reddy*}

Department of Ophthalmology, Faculty of Medicine and Defense Health, National Defense University of Malaysia, Kuala Lumpur, Malaysia. (e-mail: profscreddy@gmail.com)

*Corresponding Author teaching in the presence of a patient and is thought to be applicable only to the hospital setting [2]. Small groups of students are placed for bedside teachings. Bedside teaching is a vital component of medical education and one of the most effective ways to learn clinical and communication skills. For many years, trained simulated patients have been used and evaluated extensively in the USA and Europe [3], [4].

The lecture is one of the oldest methods of medical teachings. Traditional lecture-based teachings which are teacher centered, are gradually phasing out [5]. It is thought that students often become passive learners; the traditional lectures encourage rote memorization and note-taking as the means of assimilating knowledge [6]. Often the student loses attention quickly and an unengaged student does not learn, meaning that learning is never passive. However, it has been suggested that a lecture should remain an option for an effective teaching tool if it describes the interaction and vigilance, focuses attention with frequent questions and 
responses [5]. Lectures are probably the best teaching method for many students in many circumstances; especially for communicating conceptual knowledge, and where there is a significant knowledge gap between the lecturer and the audience [7].

By far the majority of medical schools focus on problembased tutorial learnings as the way to promote and teach students to be self-directed learners. The tutorial class is usually a small group teaching, conducted by a tutor whose role is to facilitate and guide the students for their active participation and discussion. The students use the problem of a case or scenario to define their own learning objectives. The problem serves as a focus or stimulus for the application of problem-solving or reasoning skills [8]-[10]. Seminar-based teachings are small group classes under the guidance of a teacher; here some of the students take on teaching roles with preparing and presenting the topics in the class followed by question and answer sessions. A recent research has shown that seminar-based teaching is a more effective method for medical education compared with lecture-based teaching [11].

Electronic learning or e-learning is a term to describe online learning supported by the use of information and communications technology [12]. E-learning has become a key component of medical education as students become more electronic device literate and are intimately familiar with it. Many higher education institutions adopt web-based learning systems for their e-Learning courses called Learning Management System (LMS or ELMS). This may take a variety of forms ranging from electronic posting of course materials to more interactive models using self-directed modules, formative assessment, email, discussion boards, and other collaborative tools. Blended learning has been defined simply as the combination of face-to-face and online or electronic learning opportunities [13]. Blended learning mixes various event-based activities, including face-to-face classrooms, live or recorded e-learning, and self-paced learning. Computer-based simulations are used to teach or evaluate diagnostic or therapeutic decision making [10]. The clinicopathologic conferences (CPC) remain an exercise in deductive reasoning and clinicopathological correlation. When done properly, the CPC is a great medical educational tool [14]. The use of patient simulators in medicine is not new. One of the earliest simulators introduced in the 1970s, "Harvey" the cardiology patient simulator, has proven to be an effective tool to teach and assess bedside cardiovascular skills in both undergraduate and postgraduate training programs [15]. Integrated teaching and learning refers to when knowledge and skills from across the disciplines are called upon to address patient cases, problems, and issues to create learning experiences for students [16].

Teaching and learning medicine has been challenging both for the teachers and the learners because of the continued expansion of knowledge of medical science, development of new technology in patients' diagnosing and management, evolution of teaching and learning methods and reforms in the curriculum. Current worldwide trends in medical education reflect major shifts in educational paradigms by global reforms from didactic teacher-centered teaching to the use of problem-based, student-centered, interactive, and integrated interdisciplinary teaching curriculum that facilitates self-directed learning [6], [8], [17]. Studentcentered teaching approaches are most effective in small groups [18]. It is the learner who is at the center of the educational process and the teacher acts as a moderator or facilitator 19]. A key part of this evolution has been the increasing use of e-learning [20]. Recently, medical education has also been redefined to include a broad set of competency-based education [21]. The trends in the competency-based education includes shift of the learning objectives to learning outcomes and summative assessment to formative assessments in the medical curriculum. Flipped classroom, team-based learning, patient simulations and debates are also highly active learning strategies that have been used effectively in medical educations [5], [22]. Active learning strategies promote thinking, reasoning, problemsolving and decision-making skills.

The mission of medical education is to provide adequate learning experiences to medical students so that they become competent, safe, and caring doctors [17]. Providing appropriate teaching methods in the curriculum have a great impact on learning. By identifying medical students' preferred teaching and learning methods, medical institutions may intervene to optimize their learning experience and achieve a better academic outcome. Studies have shown that multimodal learning (visual, auditory, read/write, and the kinesthetic) style is the preferred method among medical students [23], [24]; hence, the teaching and learning activities should include a blend and filled with a variety that stimulates all the four sensory modalities. It is essential for the teachers to include more images, diagrams, flow charts, algorithms, graphs, and video clips in their PowerPoint presentations (PPT) to enhance the interest and learning of the students.

\section{OBJECTIVES}

The aim of this study is to investigate the clinical medical students' preferred teaching methods provided by the medical faculty of National Defense University of Malaysia (NDUM). The questionnaire and the study design were prepared before the COVID-19 pandemic. During the COVID-19 pandemic, much emphasis on "online teaching and assessments" was provided by the institution. Therefore, those online teachings and assessment methods were not included in this study.

\section{MATERIALS AND METHODS}

This study was conducted among 89 clinical medical students of year 4 and 5 of the Faculty of Medicine and Defense Health, National Defense University of Malaysia (NDUM), Kuala Lumpur, from 1st November 2019 to 31st July 2020. It was carried out in one of the clinical teaching premises named Hospital Angkatan Tentera Tuanku Mizan (Tuanku Mizan Military Hospital), Kuala Lumpur. The medical program at this institute is for a period of 5 years; the initial 2 years are a pre-clinical program and the subsequent 3 years are clinical. After qualifying the final professional examination, the student is awarded a Doctor of Medicine (MD) degree.

Inclusion criteria of the study were: 
1. adult male and female undergraduate medical students undergoing the MD degree course;

2. placed in clinical rotations;

3 . belonging to 4 th year and 5 th (final) year;

4. supplementary candidates of final professional examination.

Exclusion criteria were:

1. the students unwilling to be included in the study;

2. incomplete/ inadequate response to the questionnaire.

Sampling was made from the students available in the $4^{\text {th }}$ and $5^{\text {th }}$ year of the medical course.

A structured data collection questionnaire was prepared and validated. Eleven questions were selected to investigate the students 'preferred methods of teaching' by the educators. The questions were constructed in a simple way so that it was easy to understand, and every question could be answered. This study was approved by the research and ethics committee of NDUM. Informed consent was obtained from all the individuals who participated in the study.

The respondents were informed that their identity would not be revealed to anyone and the confidentiality of the participants will be maintained. They were free either to participate or not in the study. Data collections were done by the authors. After a brief and clear explanation of the purpose and procedure of the study, the questionnaire was distributed to the students to give their response. Students responded anonymously to the study questionnaire. All participants were asked to tick one of their appropriate responses against the questions. Questionnaires only found to have been answered completely (total of 89) were entered and analyzed in the Statistical Package for Social Sciences (SPSS) version -20 .

\section{RESULTS}

Out of 89 students, 46 were males $(51.7 \%)$ and $43(48.3 \%)$ were females. The mean age was found to be 23.5 years (range 23-27 years). Bedside teaching was preferred by $76.4 \%$ of students followed by lectures (14.6\%) (Fig. 1).

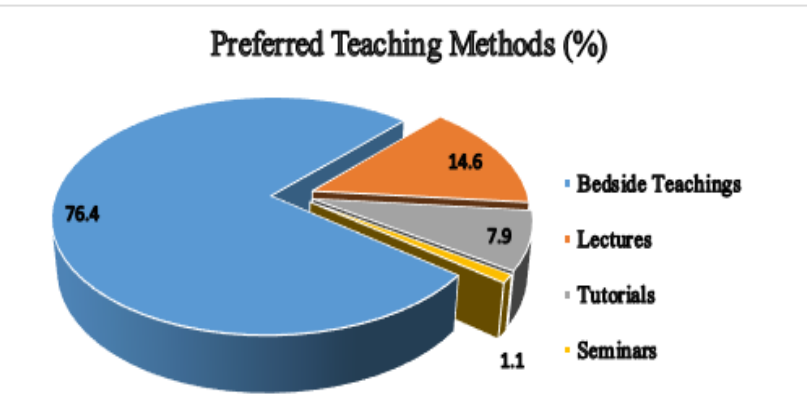

Fig. 1. Preferred Teaching Methods by the Clinical Medical Students $(n=89)$.

When asked whether CSL sessions were useful or not for improving the clinical skills, $77.5 \%$ of students answered positively (Table I). $46.1 \%$ of students would prefer to introduce a patient simulation teaching system in the medical colleges. $66.3 \%$ of students would use e-learnings' uploaded teaching materials, whereas the remainder would not.
Integrated learning activities were preferred by $76.4 \%$ of students. CPC was preferred by $60.7 \%$ of students.

TABLE I: Students’ Responses for Questions on Teaching Methods

\begin{tabular}{|c|c|c|}
\hline \multirow{2}{*}{ Questions } & \multicolumn{2}{|c|}{ Answers } \\
\hline & Number & $\%$ \\
\hline \multicolumn{3}{|c|}{$\begin{array}{l}\text { Do you feel clinical skill lab (CSL) sessions } \\
\text { useful in improving clinical skills? }\end{array}$} \\
\hline Yes & 69 & 77.5 \\
\hline No & 3 & 3.4 \\
\hline Not sure & 17 & 19.1 \\
\hline \multicolumn{3}{|c|}{$\begin{array}{l}\text { Do you think that simulation based teachings } \\
\text { and learnings should be practiced in clinical } \\
\text { years? }\end{array}$} \\
\hline Yes & 41 & 46.1 \\
\hline No & 18 & 20.2 \\
\hline Not sure & 30 & 33.7 \\
\hline \multicolumn{3}{|c|}{$\begin{array}{l}\text { Do you use e-learning (online uploaded } \\
\text { teachings/lecture slides, etc.)? }\end{array}$} \\
\hline Yes & 59 & 66.3 \\
\hline No & 30 & 33.7 \\
\hline \multicolumn{3}{|c|}{$\begin{array}{l}\text { Do you prefer integrated learning activity } \\
\text { (ILA)? }\end{array}$} \\
\hline Yes & 68 & 76.4 \\
\hline No & 4 & 4.5 \\
\hline Not sure & 17 & 19.1 \\
\hline \multicolumn{3}{|c|}{$\begin{array}{l}\text { Do you prefer clinico-pathological } \\
\text { conferences }(C P C s) \text { ? }\end{array}$} \\
\hline Yes & 54 & 60.7 \\
\hline No & 9 & 10.1 \\
\hline Not sure & 26 & 29.2 \\
\hline
\end{tabular}

TABLE II: STUDENTS' RESPONSES FOR QUESTIONS ON VARIOUS CHARACTERISTICS OF TEACHINGS AND LEARNINGS (N=89)

\begin{tabular}{|c|c|c|}
\hline \multirow{2}{*}{ Questions } & \multicolumn{2}{|c|}{ Answers } \\
\hline & Number & $\%$ \\
\hline \multicolumn{3}{|c|}{$\begin{array}{l}\text { Which one of the following is the most } \\
\text { preferred choice of teaching and learning } \\
\text { for your clinical skill? }\end{array}$} \\
\hline Bed side demonstrations & 69 & 77.5 \\
\hline Video observation & 10 & 11.2 \\
\hline Attending clinics & 4 & 4.5 \\
\hline Hospital rounds & 6 & 6.7 \\
\hline \multicolumn{3}{|c|}{$\begin{array}{l}\text { Which one is the most preferred method } \\
\text { of your learning by practicing a skill? }\end{array}$} \\
\hline On real patients & 84 & 94.4 \\
\hline On simulated patients & 3 & 3.4 \\
\hline On mannequins & 2 & 2.2 \\
\hline \multicolumn{3}{|c|}{$\begin{array}{l}\text { During teaching in class which one is } \\
\text { your most preference? }\end{array}$} \\
\hline Power point presentation & & 7.9 \\
\hline Use of board and marker pen & 21 & 23.6 \\
\hline Both & 61 & 68.5 \\
\hline \multicolumn{3}{|c|}{$\begin{array}{l}\text { Do you prefer problem based teachings } \\
\text { in the class? }\end{array}$} \\
\hline Yes & 80 & 89.9 \\
\hline No & 3 & 3.4 \\
\hline Not sure & 6 & 6.7 \\
\hline \multicolumn{3}{|c|}{$\begin{array}{l}\text { Do you like asking you questions by the } \\
\text { teachers in classes? }\end{array}$} \\
\hline Yes & 50 & 56.2 \\
\hline No & 10 & 11.2 \\
\hline Not sure & 29 & 32.6 \\
\hline
\end{tabular}

Table II shows the various teaching characteristics preferred by the students. Bedside teaching with demonstrations of a skill by the teachers was preferred by the majority $(77.5 \%)$ of the students, while observing the doctors with patients in the clinics was the least preferred method (4.5\%). Practicing skills by the students with a real patient was preferred $(94.4 \%)$ over practicing those on a simulated patient or a mannequin. While in the face-to-face classroom- 
based learning sessions, $68.5 \%$ of students preferred both combined methods using board and marker pen as well as power point presentations (PPT). Regarding case discussion, problem-based learnings (PBL) were preferred by $80 \%$ of students. Asking questions to a student in a class by a teacher was preferred by $56.2 \%$ of total students, whereas the remainder would either not prefer or not be sure of that.

\section{DISCUSSION}

In this study, among the various teaching methods adopted in the institute, bedside teaching was preferred by the majority of the students $(76.4 \%)$. Holambe et al [17] in his study in a medical school of India conducted on 138 medical students, also found that the majority of the students $(85 \%)$ preferred bedside teachings. In bedside teachings, the group of students is small, and there is a direct face to face interaction among the students and the teacher. A study in one of the Malaysian medical institutes revealed that the students enjoyed learning in small group teaching $(48.6 \%)$ and bedside clinical teaching $(47.9 \%)$ compared to the lectures $(12 \%)$ [25]. Clinical and communication skills are better developed in bedside teachings. It appears that face-to-face bedside teachings have a great impact on clinical learnings by the medical students. It should comprise the bulk of the schedules of the teaching methods for clinical students.

When asked whether CSL sessions were useful or not, most of the students $(77.5 \%)$ were in favor of CSL sessions using mannequins or simulators for improving their clinical skills. Holambe et al [17] found mannequins and demonstrations were the preferred teaching method next to bedside teachings. Students prefer mannequins during CSL sessions to increase their confidence and gain practical experience. In this study, $46.1 \%$ of students would prefer to introduce a patient simulation teaching system in the university. Lujan et al [26] has reported an increase in students' achievement with the use of simulations, and students usually express positive feelings from their experiences. $66.3 \%$ of students of the current study would use the university e-learnings' uploaded teaching materials. The common theme is one of engagements, with students using online resources mainly to interact with course content and gauge their knowledge and progress [27]. The students use these uploaded teaching materials at a time convenient to them.

Integrated learning activities were preferred by $76.4 \%$ of students. In a study, it was found that students are interested in more bedside and interactive learning sessions; often less interested in interdisciplinary sessions [17]. The CPC was preferred by $60.7 \%$ of students because it helps in the integration and interpretation of preclinical knowledge obtained earlier to the pathogenesis of the disease and its pharmacotherapeutics.

Demonstrations by the teachers of a clinical skill during bedside teachings in the ward was preferred by a majority $(77.5 \%)$ of the students, rather than while observing those during hospital rounds $(6.7 \%)$ and in the outpatient clinics $(4.5 \%)$. The study showed that practicing skills on a real patient was preferred $(94.4 \%)$ over practicing on simulated patients or mannequins. This is because in the bedside teaching, there is scope to demonstrate the correct way of eliciting the signs in different systems of the body and also to correct the students' method of the same if not done in the acceptably standard method.

During face-to-face classroom-based learning sessions, $68.5 \%$ of students in this study preferred both using whiteboard and marker pen combined with PPT. $23.6 \%$ of subjects had a preference for the use of board and marker pen only and $7.9 \%$ preferred PPT. In one study, the majority of undergraduate medical students (419 out of 540), preferred traditional blackboard teaching than slide-projection or PPT class [28]. Holambe et al [17] found the traditional chalk and talk method and PPTs almost equally preferred through a mix of aids. However, a study conducted in Pakistan by Atif et al, found that the PPT was the most preferred aid with white board being the least favorite [29].

In teaching sessions, problem bases learning was preferred by a huge number of students $(80 \%)$ in this study. Asking questions to a student in a class by the teacher was preferred by $56.2 \%$ of total students, whereas the remainder would either not prefer or not be sure of that. The study conducted by Ismail et al, in one of the medical institutes of Malaysia, revealed that majority of students believe PBL is the best way to access critical thinking and for development of understanding [8].

\section{CONCLUSION}

Providing the methods of teaching as preferred by the students will enhance their interest and learning. This study revealed that face to face bedside teaching in a hospital setting is mainly preferred by the clinical students. Most of the students, learn after observing the bedside demonstrations provided by a teacher as well as by practicing themselves the skills on a patient. The students prefer learning of clinical skills by practicing on a real patient rather than on a simulated patient, or mannequin in a lab. Therefore, they should be placed in the hospital most of the period of their clinical rotations. However, the students also feel CSL sessions are useful in learning and improving their clinical skills. The institutes should provide sufficient number of manikins and patient simulators for the students to practice various clinical skills, bedside procedures, and clinical problems. Problem based learning sessions are preferred by large number of students. Adequate teaching materials uploaded in the elearning system provide one of the best resources for learnings by the students.

\section{LIMITATIONS OF THE STUDY}

There are some limitations to this study. First, the study was conducted among the clinical medical students of one medical institution in Kuala Lumpur. Hence, the findings of this study may not reflect the actual preference of teaching methods of the clinical students of all the medical institutions of the country. Second, the questionnaire and the study design were prepared before the COVID-19 pandemic, part of the study was conducted during the pandemic crisis. The students were deprived of face-to-face bedside teachings in hospitals, which may influence some aspects of answering the questionnaires by some students. The important limitation is 
a small sample size of the study population.

\section{ACKNOWLEDGEMENT}

We are grateful to the Dean, Faculty of Medicine and Defense Health, NDUM, for giving us the opportunity for conducting the study. We are thankful to the staff of the faculty for allowing us to use the stationeries, papers, printer machines, etc. and for the assistance to conduct the study. Lastly, we extend our sincere thanks to all the students for their participation and honest responses in the study.

\section{AUTHORS' CONTRIBUTIONS}

This work was carried out in collaboration between both the investigators. Author SSA designed the study, managed the literature search, wrote the protocol and the draft of the manuscript. Both the authors developed the questionnaire and collected the data from the study subjects. Author SCR performed data entry and analysis. Both the authors read, revised, and approved the final manuscript.

\section{REFERENCES}

[1] Papanna KM, Kulkarni V, Tanvi D, Lakshmi V, Kriti L, Unnikrishnan $\mathrm{B}$, et al. Perceptions and preferences of medical students regarding teaching methods in a Medical College, Mangalore India. Afr Health Sci. 2013;13(3):808-13.

[2] Salam A, Siraj HH, Mohamad N, Das S, Rabeya Y. Bedside Teaching in Undergraduate Medical Education: Issues, Strategies, and New Models for Better Preparation of New Generation Doctors. Iran J Med Sci. 2011 Mar; 36(1):1-6.

[3] Barrows HS, Abrahamson S. The programmed patient: a technique for appraising student performance in clinical neurology. J Med Educ 1964;39:802-5.

[4] Stillman PL, Regan MB, Philbin M, Haley HL. Results of a survey on the use of standardised patients to teach and evaluate clinical skills. Acad Med 1990;65:288-92.

[5] Schwartzstein RM, Roberts DH. Saying Goodbye to Lectures in Medical School - Paradigm Shift or Passing Fad? Perspective. N Engl J Med. 2017; 377(7):605-607.

[6] Gwee MCE. Commentary in "Medical Education: Issues, Trends, Challenges \& Opportunities". SMA News. 2003(35(2):5-8.

[7] Charlton BG (Editor in Chief). Lectures are such an effective teaching method because they exploit evolved human psychology to improve learning. Medical Hypotheses. 2006;67(6):1261-1265.

[8] Ismail S, Rahman NIA, Mohamad N, Jusoh NM, Hood AIB, Arif LAB. Preference of Teaching and Learning Methods in a new Medical School of Malaysia. J App Pharm Sci. 2014;4(02):048-055.

[9] Dacre JE, Fox RA. How should we be teaching our undergraduates? Annals of the Rheumatic Diseases. 2000;59(9):662-667.

[10] Seifer SD. Recent and emerging trends in undergraduate medical education-curricular responses to a rapidly changing health care system. West j Med. 1998;168:400-411.

[11] Zeng HL, Chen DX, Li Q, Wang XY. Effects of seminar teaching method versus lecture-based learning in medical education: A metaanalysis of randomized controlled trials, Medical Teacher, 2020;42(12):1343-1349.

[12] Academy of Medical Royal Colleges. The development of e-learning for doctors. 2007. Retrieved December 3, 2020, from http://www.aomrc.org.uk/news.aspx.

[13] Dziuban CD, Hartman JL, Moskal PD. Blended Learning. Educause Research Bulletin.2004;7:2-12.

[14] Hajar R. The Clinicopathologic Conference. Heart Views. 2015;16(4):170-173.

[15] Harden RM. Trends and the future of postgraduate medical education. Emerg Med J. 2006;23(10):798-802.

[16] Vyas R, Sathishkumar S. Recent Trends in Teaching and Learning in Physiology Education Early Clinical Exposure and Integration. International Journal of Basic and Applied Physiology. 2012;1(1):175181.
[17] Holambe VM, Thakur NA, Giri PA. Student's preferences for learning in medical education. Int $\mathbf{J}$ Community Med Public Health. 2015;2(3):328-330.

[18] Newble D, Cannon R. A handbook for medical teachers. Kluwer Academic Publishers, Boston, 1994. pp 38-53.

[19] Van Der Vleuten CPM, Dolmans DHJM, Scherpbier AJJA. The need for evidence in education. J of Medical Teacher. 2000;22(3):246-250.

[20] Morton CE, Saleh SN, Smith SF, Hemani A, Ameen A, Bennie TD, et al. Blended learning: how can we optimise undergraduate student engagement? BMC Medical Education. 2016;16:195.

[21] Davidson LK 2009. Educational Innovation in an Undergraduate Medical Course Implementation of a Blended e-Learning, Team-Based Learning Model. A thesis submitted to the Faculty of Education in conformity with the requirements for the degree of Master of Education. Queen's University, Kingston, Ontario, Canada January, 2009.

[22] Kumar LJ, Voralu K, Pani SP, Sethuraman KR. Predominant Learning styles adopted by AIMST University students in Malaysia. South East Asian Journal of Medical Education. 2009;3(1):37-46.

[23] Ahmed SS, Reddy SG. Preferred Learning Style and Study Characteristics: A Study Among Undergraduate Clinical Medical Students of National Defense University of Malaysia. Journal of Advances in Medicine and Medical Research. 2020;32(19):51-60.

[24] Soundariya K, Deepika V, Kalaiselvan G. A study on the learning styles and learning approaches among medical students. Natl J Physiol Pharm Pharmacol. 2017;7(10):1020-1025.

[25] Swe KMM, Wen CA, Kumar SJ, Bhardwaj A. Learning Style Preferences of Medical Students in Perdana University-Royal College of Surgeons in Ireland School of Medicine, Malaysia. British Journal of Medicine \& Medical Research. 2016;18(3):1-8.

[26] Lujan LH, Dicarlo SE. Too much teaching, not enough learning: what is the solution? Advances in Physiology Education. 2006;30:17-22.

[27] Twigg CA. Improving learning and reducing costs: New models for online learning. Educause Review. 2003;38(5):28.

[28] Novelli ELB, Fernandes AAH. Students' Preferred Teaching Techniques for Biochemistry in Biomedicine and Medicine Courses. Biochemistry and Molecular Biology Education. 2007;35(4):263-266.

[29] Atif M, Famidha K, Mukarram A, Saima E, Kamran A, Masood AQ Perception and preferences of undergraduate medical students regarding the use of contemporary teaching aids at Dow international medical college, Karachi. Journal of University of Health Sciences Karachi. 2011;5(1):34-6. 